\title{
On the Logic of Business Plan Composition
}

\author{
Jeff Trailer \\ Chester Wolford
}

Effective business plans do not live by their topics alone: how well the analysis of those topics persuades is at least as important. Analytical writing draws conclusions by investigating and synthesizing facts and conjectures. Synthesizing facts and conjectures into sound arguments requires deductive logic. Deductive logic, then, provides a set of rules to help people write sound business plans. This article presents examples for improving the effectiveness of business plans by focusing on the logical structure of their composition.

$\mathbf{E}$ ffective business plans are so important to small business that much practitioner ink has been spilled over the topics to be included in them. For example, Hacker (1997) presents a 17- step process (topics) to construct a plan; Hawk (1997) outlines 17 subheadings (topics) to be used as a guide to writing a plan; Sahlman (1997) discusses four interdependent factors (topics) critical to every venture; Schneider (1998) outlines 9 sections (topics) that represent critical elements in a comprehensive plan; Siegel (1999) offers 10 questions (topics) that should go into the standard plan.

Given that the important topics have been identified, little academic work has followed on actually writing the business plan (Vesper, 1997). Perhaps as a consequence, the effectiveness of arguments made about these topics has been slighted. Ultimately, the entrepreneur must write a logical assessment of these issues, or the list of critical issues is just that... a list. Thus, Bygrave (1994; 137), complains that "Entrepreneurs often get bogged down in the actual mechanics of writing. The material often comes out too conceptual or disorganized, and they don't know how to fix it."

Merely listing the important topics in a business plan creates only generalities. Details must support the arguments made about and for the topics. And arguments persuade (Beene and Douglas, 1989). That is, effective business plans are the outcome not only of covering all the bases, but also of covering them well. When covered well, business plans produce strong conclusions regarding the feasibility of starting a business, establish milestones and performance goals, assess the safety of the business for lenders, and so on (Bardell, 1988). Analytical writing draws conclusions from the investigation and synthesis of facts and conjectures, or both (Popper, 1989). Synthesizing facts and conjectures into sound arguments requires deductive logic. Consequently, deductive logic provides a set of rules to help people write effective business plans.

\section{Definitions}

Before discussing the structure of persuasive, analytical business plans, we need some definitions.

\section{Composition}

Just as spelling dictates the rules for constructing words and grammar dictates the rules for creating sentences, composition properly arranges sentences within the larger structure of argument: sentences into paragraphs, paragraphs into chapters, and so on.

With few immutable rules, composition is enormously time-consuming to learn and expensive to teach well (Capaldi, 1966; Johnson, 1982). Poor composition may simultaneously produce documents that are grammatically perfect, yet utterly unpersuasive, or even incoherent. Good composition in business plans, then, is crucial. Clearly, business plans benefit from meaningful, persuasive argument, for which there are rules.

\section{Statements}

Statements are either analytic or synthetic (Kant, 1787).

Analytic Statements. These statements are true by definition and do not require the confirmation of external facts. To say, "I believe Bill Gates is rich," requires no external support. Neither does stating, "The goal of my firm is to achieve 20 percent growth in sales each year." The truth of these statements is defined by the writer/owner, and the reader must assume their truth.

Synthetic Statements. These statements, conversely, may be true only if external facts support them. To say "Bill Gates is rich," or "this is a feasible new venture" requires more than assertion to make it true; Bill Gates is not rich and new ventures are not feasible by definition. The statements are only as "true" as the supporting arguments are true, or in business, true to the degree that they persuade readers.

Persuasive business plans require synthetic statements. That is, a business plan requires a synthesis of external facts to support its validity. Deductive logic provides the rules for synthesizing statements to create sound arguments. 


\section{Arguments}

Arguments are the means by which a writer persuades the reader (Beene and Douglas, 1989). Arguments persuade readers to the degree that the writer's logic is sound, where soundness is defined as an argument in which the premises are true and the conclusion follows necessarily from those premises. As premises are typically declarative statements, arguments typically comprise a conclusion and two or more premises. The basic structure of argument is the syllogism (see Exhibit 1 for alternative, generic structures):

Premise (major): The general rule for success

Premise (minor): A specific case or example of the general rule

Conclusion: Thus, this example indicates (future) success/failure
Syllogisms comprise a major premise, a minor premise and a conclusion (Hurley, 1982). The major premise states the general rule. The minor premise states fact, observation, or example that fall within the domain of the general rule. The conclusion synthesizes the major and minor premises, applying the general rule to the specific case.

Valid conclusions satisfy two conditions: they follow necessarily from the premises, and they grant the truth of the premises. The premises do not have to be true; the conclusion simply must follow logically from them if they are true. For example, the following is a valid but unsound syllogism (valid conclusion, but incorporates a flawed premise).

Major premise: All successful dry cleaning businesses are located on the South side of the street.

Minor premise: Frank's Dry Cleaning will be located on the South side of State Street.

Conclusion: Therefore, Frank's Dry Cleaning has a good location.

\begin{tabular}{|c|c|}
\hline \multicolumn{2}{|c|}{$\begin{array}{c}\text { Exhibit 1 } \\
\text { On the Structure of Analytical Writing: The Syllogism }\end{array}$} \\
\hline Argument type I: & Classical order, with the conclusion at the end \\
\hline $\begin{array}{l}\text { Premise (major): } \\
\text { Premise (minor): } \\
\text { Conclusion: }\end{array}$ & $\begin{array}{l}\text { The general rule for success } \\
\text { A specific case or example of the general rule } \\
\text { The example indicates (future) success/failure. }\end{array}$ \\
\hline Argument type II: & Conclusion between premises \\
\hline $\begin{array}{l}\text { Premise (major): } \\
\text { Conclusion: } \\
\text { Premise (minor): }\end{array}$ & $\begin{array}{l}\text { The general rule for success } \\
\text { The example indicates (future) success/failure } \\
\text { A specific case or example of the general rule }\end{array}$ \\
\hline Argument type III: & Conclusion at the beginning \\
\hline $\begin{array}{l}\text { Conclusion: } \\
\text { Premise (major): } \\
\text { Premise (minor): }\end{array}$ & $\begin{array}{l}\text { The example indicates (future) success/failure } \\
\text { The general rule for success } \\
\text { A specific case or example of the general rule }\end{array}$ \\
\hline Argument type IV: & Extending beyond the syllogism \\
\hline $\begin{array}{l}\text { Conclusion: } \\
\text { Premise (major): } \\
\text { Premise (minor): }\end{array}$ & $\begin{array}{l}\text { The example indicates (future) success / failure } \\
\text { The general rule for success } \\
\text { A specific case or example of the general rule }\end{array}$ \\
\hline $\begin{array}{l}\text { Premise (a): } \\
\text { Premise (b): } \\
\text { Premise (c): } \\
\text { Premise (d): }\end{array}$ & $\begin{array}{l}\text { A specific point or example in the case } \\
\text { A specific point or example in the case } \\
\text { A specific point or example in the case } \\
\text { etc. }\end{array}$ \\
\hline
\end{tabular}


Even when true premises are incorporated, an invalid argument may result (flawed conclusion):

Major premise: In our county, all dry cleaning business locations must meet $\mathrm{C}-2$ zoning requirements.

Minor premise: "Frank's" is a dry cleaning business.

Conclusion: Therefore, Frank's location on State Street meets our county's zoning requirements.

Although the premises in the above example are true, the conclusion cannot necessarily be drawn from them. This is called a non-sequitur.

Thus, an argument may be unpersuasive because it is either invalid, or valid but unsound. Alternatively, an argument is sound only if two conditions are satisfied: the premises are true and the conclusion follows necessarily from them (Hurley, 1982). For example, to persuade the reader that a firm is liquid the writer may construct the following argument:

Major premise: Liquidity may be assessed by current ratio (current assets divided by current liabilities), which, if greater than one, indicates that the firm can pay liabilities coming due within one year with assets that may be turned into cash within one year.

Minor premise: For this new venture, the current ratio is 1.2 .

Conclusion: Thus, the firm is liquid.

The conclusion, "the firm is liquid," is a synthetic statement made persuasive by the major and minor premises (Beene and Douglas, 1989). Note that the relative order in which the premises and conclusion are written has no effect on the logic of the argument, and may be rearranged to increase rhetorical persuasiveness (Hurley, 1982). Here are examples:

\section{Argument type I: $\quad$ Classical order, with the conclu- sion at the end}

Premise (major): Liquidity may be determined by a current ratio greater than 1 .

Premise (minor): This firm has a current ratio of 1.2 .

Conclusion: For this venture, the firm is liquid.

Argument type II: Conclusion between premises
Premise (major): Liquidity may be determined by a current ratio greater than 1 .

Conclusion:

For this venture, the firm is liquid.

Premise (minor): This firm has a current ratio of 1.2 .

Argument type III: Conclusion at the beginning

Conclusion:

For this venture, the firm is liquid.

Premise (major): Liquidity may be determined by

a current ratio greater than 1.

Premise (minor): This firm has a current ratio of 1.2 .

A fourth type of argument moves beyond the simple syllogism by incorporating several (or many) minor premises, while retaining the major premise and conclusion: overkill for syllogisms but sometimes necessary for persuasion.

Argument type IV: Extending beyond the syllogism

Conclusion: $\quad$ For this venture, the firm is liquid.

Premise (major): Liquidity may be determined by a current ratio greater than 1.

Premise (minor): This firm has a current ratio of 1.2.

Premise (a): This firm's ratio for 1996 was 1.7 .

Premise (b): This firm's ratio for 1995 was 1.7 .

Premise (c): This firm's ratio for 1994 was 1.1.

Premise (d): This firm's ratio for 1993 was 1.4 .

Premise (e): This firm's ratio for 1992 was 1.1.

The minor premises may be arguments themselves (Capaldi, 1966). Multiple premises, and arguments within arguments, are important in business plans, given that the goal of a business plan cannot typically be explained with a single, simple syllogism. Reducing the plan to a single argument may be logically valid, but not likely to persuade. For example, a business feasibility analysis may be written as follows: 


\section{Exhibit 2 \\ Business Plan}

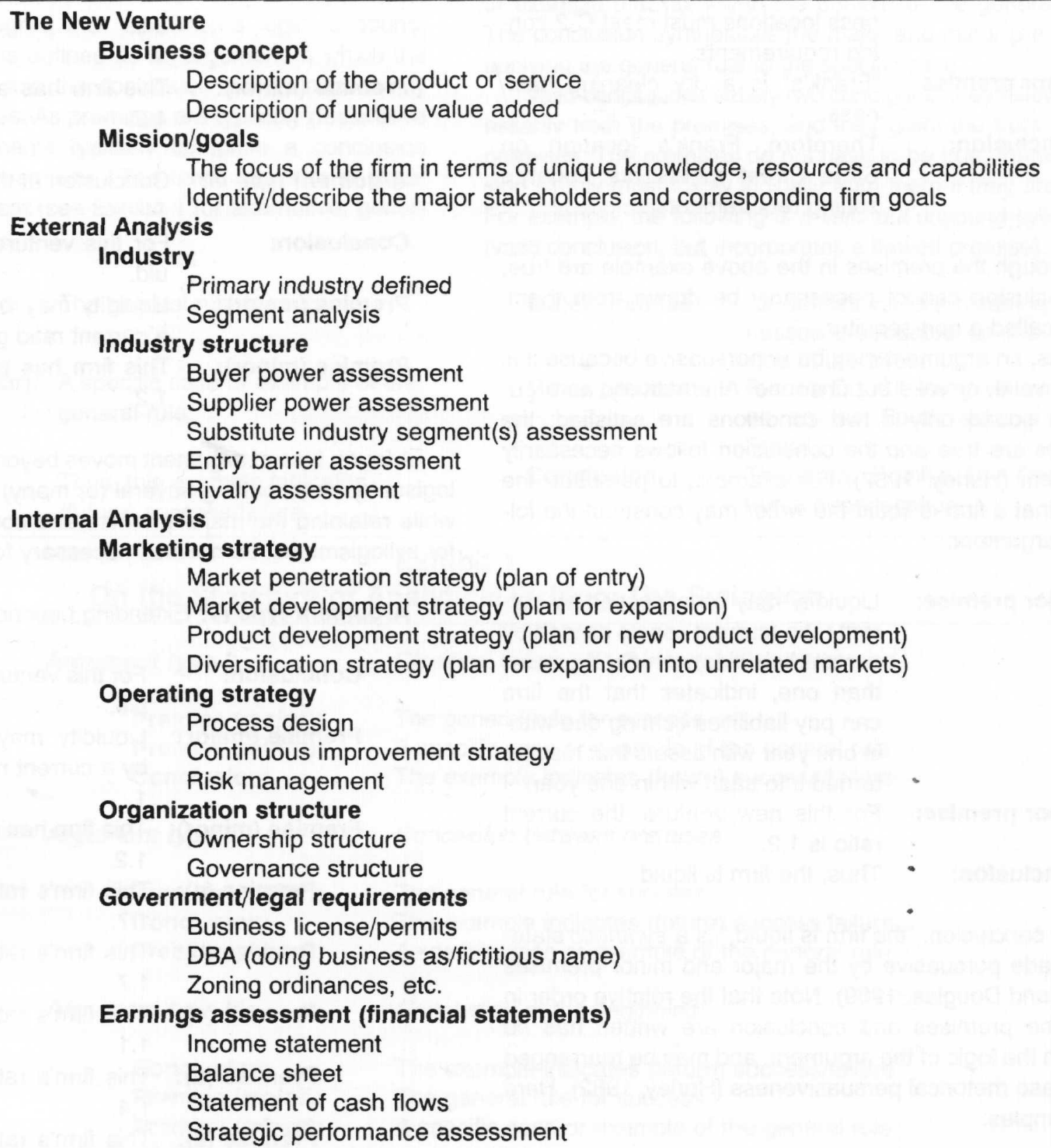

Major premise: A feasible business earns profits sufficient to cover its cost of capital.

Minor premise 1: The projected cost of capital for this firm is 15 percent.

Minor premise 2: The projected return on assets for this firm is 20 percent.

Conclusion: This is a feasible business.

If the premises are true, this argument is sound. Even so, because the argument is probably not in itself sufficiently persuasive, or even useful, to the entrepreneur, additional arguments are necessary. Incorporating multiple arguments creates more precision in explaining the firm's performance, is more persuasive as a consequence, and is thus more likely to be successful (Beene and Douglas, 1989).

Arguments are good building blocks for business plans. Assembling the blocks is guided by the topic outline. 
The outline, in turn, is guided by the goal of the plan. A plan organizes a task. Tasks in new venture formation may include a feasibility analysis, specific goals for subsequent organizational control, and a prospectus for external investors, among others. Because business plans vary as greatly as the businesses they describe, no single structure suits all plans. To focus further discussion, however, a generic, comprehensive business planning analytical framework is provided in Exhibit 2.

\section{Business Plan Topics and Their Independence}

The first argumentative questions regarding the structure of business plans are conceptual:

-What are the major topics?

-Why are these particular topics discussed?

Answering these questions is the key to logical construction because they establish the major premise, or framework, of the plan. That is, the topics discussed are not selected at random but selected because they are required in order to draw a sound conclusion on the topic. Thus, for a plan to be persuasive it must always warn the reader what is going to be discussed, and why. This leads to the second question: In what order shall the topics be discussed? Answering this question depends on whether the topics are independent of each other. If the topics are independent, then the order of discussion is a matter of style, not logic. This is called a compound argument structure. If the topics are interrelated, then they must be discussed in their proper order, or sequence. This is a sequence dependent argument structure.

The generic business plan example below includes three major topics. The first, The New Venture, is predominately a set of analytic statements defining the business to be analyzed in the plan. The rest of the plan is predominantly synthetic and is divided into discussions of two influences on the firm's performance: the External Environment, over which the venture has little or no control; and the Internal Environment, which the firm can influence. The overall conclusion drawn from the external environment is an assessment of the new firm's survival requirements. The overall conclusion to be drawn from the internal environment is an assessment of the new firm's performance that results from the manner of its operation. The overall conclusion of the internal environment, however, depends partially on the conclusion drawn from the external environment. "Competitive" firms, then, produce a product or service differentiated from or produced at a lower cost than that of the competition (Porter, 1980). In either case, assessing competitiveness requires synthesizing conjectures about the capabilities of the firm with the assessment of the competitive environment. Such sequential dependence between arguments is common (Capaldi,

\section{Exhibit 3 \\ On the Structure of Analytical Writing: Sequence Dependent Arguments}

Topic 1

\section{Argument 1}

Premise 1 (major): $\quad$ Introduce the topic and discuss the general rule.

Premise 1 (minor): A specific case or example of the general rule.

Conclusion 1: Thus, this example indicates...

\section{Argument 2}

Premise 2 (major):

The general rule, encompassing the conclusion of premise 1.

Premise 2 (minor):

A specific case or example of the general rule.

Conclusion 2:

Thus, this example indicates...

\section{Argument 3}

Premise 3 (major): The general rule, encompassing the conclusion of premise 2.

Premise 3 (minor): A specific case or example of the general rule.

Conclusion (for Argument 3 and the topic):

Thus, this example indicates... 
1966; see Exhibit 3 for an overview of this generic structure). For example:

Topic 1

Argument 1: The New Venture

Premise 1 (major): To be "competitive" a firm must produce a product or service differentiated from or produced at a lower cost than that of the competition. In either case, to be profitable a firm must possess a unique capability. This business plan will assess the competitiveness of the proposed new venture by describing the business concept, assessing the competitive environment, and assessing the internal capabilities of the firm.

Premise 1 (minor): The proposed venture will help entrepreneurs to write logically sound business plans. While several consulting firms help entrepreneurs write business plans, none specializes in writing them logically.

Conclusion 1: Thus, the unique capability of this venture is that of creating superior business plans by making them formally and informally logical.

\section{Argument 2: The External Environment}

Premise 2 (major): The market price of business plan writing assistance is constrained by the price of close substitute services offered in the market.

Premise 2 (minor): In this market, three firms currently offer assistance in writing business plans. The firms charge $\$ 495$ to $\$ 500$ for the same approximate level of service to be provided by our proposed firm. However, our service will produce superior results by adding sound, logical arguments to business plans.

Conclusion 2: Thus, the market price for our business plan writing assistance will be equal to, or slightly higher than the competition's. Conservatively estimating performance, the firm will set an initial price equal to the competition's upper boundary: $\$ 500$.

\section{Argument 3: $\quad$ The Internal Environment}

Premise 3 (major): To be profitable, the firm must be structured to provide customer service at a total cost per unit sold of less than $\$ 500$. Further, the return to the owners must exceed the opportunity salary cost to the owners.

Premise 3a (minor):

The proposed firm structure will provide a per unit cost of $\$ 100$ at the projected sales volume level of ten units a month, producing net profits of $\$ 4,000$ a month.

Premise 3b (minor):

The salary opportunity cost to the owners is $\$ 3,000$ a month.

Conclusion: Thus, this is a feasible new venture.

\section{Compound Arguments}

A conclusion from one topic may derive from independent arguments of its subtopics (see Exhibit 4). This is called a compound argument. Further, a premise for an argument on one level of analysis may be composed of an argument, or arguments, of a lower level, and so on. In the example below, a compound argument is used to express the solvency of a new venture as a function of cash flow analysis: three independent arguments. Notice that the overall conclusion on Total Cash Flow does not depend on the order in which the cash flow arguments are discussed.

\section{Argument I: $\quad$ Total Cash Flow}

Premise (major): A positive total cash flow is necessary for the survival of the new venture. Total cash flow is a function of three sources of cash: operations, investing, and financing. In the short run, one source may offset negative cash flow from anoth- 


\section{Exhibit 4}

\section{On the Structure of Analytical Writing: Writing Compound Arguments}

\section{Argument I (Topic 1)}

Premise (major):

Premises (major) 1,2, and 3 are necessary to draw a conclusion (the topic is a function of premises 1,2 and 3). This introduction should establish the framework for the analysis which follows, and establish the basis for drawing an overall conclusion at the end of the discussion on this topic.

Argument 1:

Premise 1 (major): The general rule

Premise 1 (minor): A specific case or example of the general rule

Conclusion 1: $\quad$ Thus, this example indicates...

Argument 2:

Premise 2 (major): The general rule

Premise 2 (minor): A specific case or example of the general rule

Conclusion 2: Thus, this example indicates...

Argument 3:

Premise 3 (major): The general rule

Premise 3 (minor): A specific case or example of the general rule

Conclusion 3: Thus, this example indicates...

\section{Summary and conclusion:}

Premise (minor) 1: $\quad$ (The conclusion of argument 1)

Premise (minor) 2: $\quad$ (The conclusion of argument 2)

Premise (minor) 3: (The conclusion of argument 3)

Conclusion for this topic: Thus, in this case...

er source. Still, the long-run feasibility of the business requires positive cash flow from operations because investing and financing activities alone cannot generate cash indefinitely.

Argument 1: Cash flow from operations

Premise 1 (major): Positive operating cash flow indicates the new venture is generating cash in its on-going operations.

Premise 1 (minor): Projected cash flow from operations is $\$ 10,000$.

Conclusion 1: Thus, this new venture is projected to generate cash from operations.

Argument 2: $\quad$ Cash flow from investing
Premise 2 (major): Positive cash flow from investing indicates the new venture is generating cash by selling assets, such as plant and equipment.

Premise 2 (minor): Projected cash flow from investing is $\$-20,000$.

Conclusion 2: Thus, this new venture is projected to consume cash from investing by purchasing assets for the new venture.

Argument 3: $\quad$ Cash flow from financing

Premise 2 (major): Positive cash flow from financing indicates the new venture is generating cash by selling equity, or incurring debt. 
Premise 2 (minor): Projected cash flow from financing is $\$ 15,000$.

Conclusion 2: $\quad$ Thus, this new venture is projected to generate cash from financing by selling equity, or incurring debt.

Summary:

Premise (minor)1: Operating activity is projected to generate $\$ 10,000$.

Premise (minor) 2: Investing activity is projected to consume $\$ 20,000$.

Premise (minor) 3: Financing activity is projected to generate $\$ 15,000$.

\section{Conclusion:}

\section{Complex Arguments}

Finally, arguments are complex if they comprise premises that, in turn, comprise both compound arguments and sequence dependent arguments (see Exhibit 5). The exam-

\section{Exhibit 5}

\section{On the Structure of Analytical Writing: Writing Complex Arguments}

Argument (Topic 1)

Premise (major): Topic 1 is a (compound) function of arguments 1 and 2 .

\section{Argument 1:}

\section{Argument 1a:}

Premise (major): $\quad$ The general rule.

Premise (minor): $\quad$ A specific case of the general rule.

Conclusion: Thus, this example indicates...

Argument 1b:

Premise (major): $\quad$ The general rule, encompassing the conclusion of premise 1.

Premise (minor): $\quad$ A specific case of the general rule.

Conclusion (for $1 \mathrm{~b}$ and Argument 1):

Thus, this case indicates...

\section{Argument 2:}

\section{Argument 2a:}

Premise 1 (major): The general rule.

Premise 1 (minor): A specific case of the general rule.

Argument 2b:

Conclusion 1: Thus, this example indicates...

Premise 2 (major): The general rule, encompassing the conclusion

of premise 1.

Premise 2 (minor): $\quad$ A specific case of the general rule.

Conclusion (for $2 \mathrm{~b}$ and Argument 2):

Thus, this case indicates...

\section{Summary and conclusion:}

Premise (minor): (The conclusion of Argument 1)

Premise (minor): (The conclusion of Argument 2) 
ples provided are intended to show that business plans are typically based on complex arguments: multiple arguments are required to justify the overall conclusion, and the individual arguments are integrated in both sequence dependent and compound structures. The intricacies of writing sound complex arguments help explain why entrepreneurs have great difficulty composing meaningful business plans, and why training in the composition of sound arguments might make business plans more effective.

\section{Conclusions}

The emphasis here on logical structure is not intended to imply that imagination and creativity are to be banished from the analytical writing process. Quite the contrary, imagination is likely critical to developing a business that will prosper. This creativity must, however, occur with discipline. This study is concerned with making creativity functional by delineating rules for analytical composition.

How many arguments are necessary for a persuasive and complete business plan? As many as necessary and not one more. Viewers of Sunday morning political-discussion shows will recognize that there the number of arguments is limitless. Business, however, must recognize limits. As a general principle, Mach (1919) argues that the best explanation is that which is most economical in use of concepts and complex relationships. Better, there is Henry David Thoreau's version of Occam's Razor: Simplify. Simplify. Simplify. Obeying both, this article closes by summarizing: Good arguments are essential to good business planning.

\section{References}

Bardell, R. 1988. "Banking on the business plan." Accountancy, 102, 1134: 65.

Beene, L.D., and K. Douglas. 1989. Argument and analysis: Reading, thinking, writing. Orlando, FL: Holt, Rinehart \& Winston.

Bygrave, W.D. 1994. The portable MBA in entrepreneurship. New York: John Wiley \& Sons, Inc.

Capaldi, N. 1966. Introduction to deductive logic. New York, NY: Monarch Press.

Hacker, R. C. 1997. "17 steps to a successful business plan." Target Marketing, 20, 2, February: 33-34.

Hawk, K. 1997 "10 weeks to a business plan." Catalog Age, 14, 7, July: 189-192 (3 pages).

Hurley, P. 1982. A concise introduction to logic. Belmont, CA: Wadsworth Publishing Co.

Johnson, E. 1982. Handbook of good English. New York: The Washington Square Press.

Kant, I. 1787. Critique of pure reason. Translated from the 2nd Edition by Norman Kemp Smith, reprinted 1929. London: MacMillan Co. Ltd.

Mach, E. 1919. The economy of science in The world of mathematics, Volume 3, Part XII. New York: Simon and Schuster, (1956): 1787-1795.

Popper, K. R. 1989. Conjectures and refutations: The growth of scientific knowledge, 5th Edition. Reprinted 1992. New York: Routledge.

Porter, M. 1980. Competitive strategy: Techniques for analyzing industries and competitors. New York: The Free Press.

Sahlman, W. A. 1997. "How to write a great business plan," Harvard Business Review, 75, 4, July-August, pp: 98108.

Schneider, T. W. 1998. "Building a business plan," Journal of Property Management, 63, 6: 30-32.

Siegel, M. D. 1999. "How to create a business plan," Folio, 27, 18: 191-192. 
Trailer, J. 1996. "Format for strategic analysis report" in Neupert, K., and J. Fry, Cases for contemporary strategy analysis. Oxford: Blackwell: xxix-xxxiv.

Vesper, K. 1997. "Missing links in entrepreneurship research." Unpublished notes accompanying the keynote speech at INTENT ' 97 conference, Monterey Bay, CA.
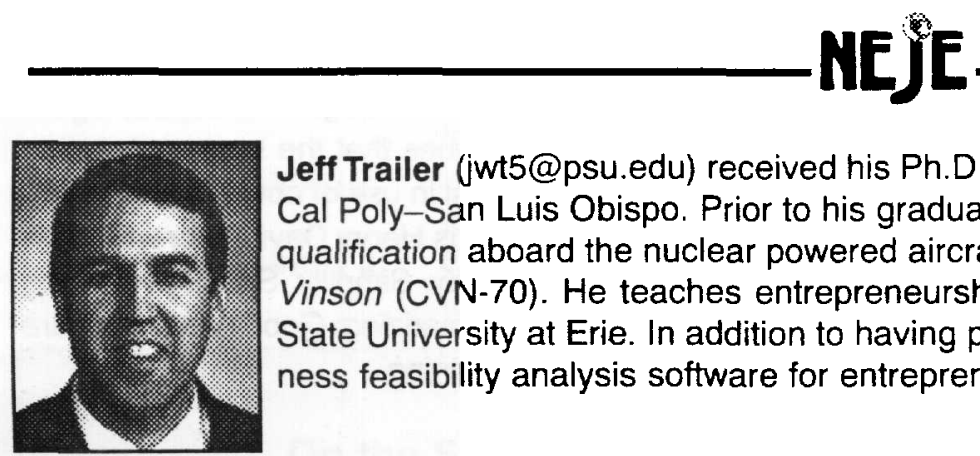

Jeff Trailer (jwt5@psu.edu) received his Ph.D. from the University of Houston and his M.B.A. from Cal Poly-San Luis Obispo. Prior to his graduate education, he earned his Surface Warfare officer qualification aboard the nuclear powered aircraft carriers USS Enterprise (CVN-65) and USS Carl Vinson (CVN-70). He teaches entrepreneurship and strategic management at the Pennsylvania State University at Erie. In addition to having published articles and books, he has published business feasibility analysis software for entrepreneurs.

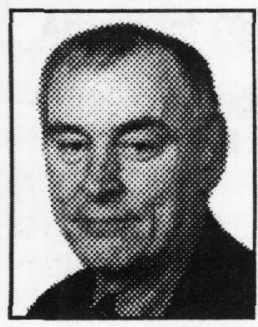

Chester Wolford (cxw3@psu.edu) has received degrees from Georgetown, Maryland and Penn State. He has published two books of literary criticism, one textbook (with G. Vanneman) and numerous articles on technical and business writing, and literary criticism. He is professor of English and business at the Pennsylvania State University at Erie. 